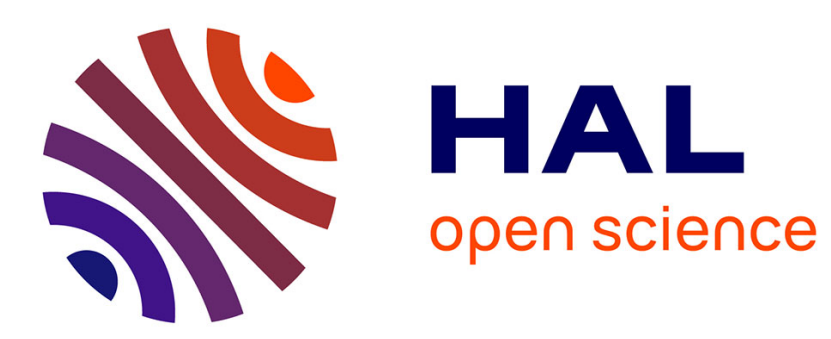

\title{
A Conceptual Framework for the Collaborative Modeling of Networked Manufacturing Systems
}

\author{
Viktor Zaletelj, Alojzij Sluga, Peter Butala
}

\section{To cite this version:}

Viktor Zaletelj, Alojzij Sluga, Peter Butala. A Conceptual Framework for the Collaborative Modeling of Networked Manufacturing Systems. Concurrent Engineering: Research and Applications, 2008, 16 (1), pp.103-114. 10.1177/1063293X07084636 . hal-00571214

\section{HAL Id: hal-00571214 \\ https://hal.science/hal-00571214}

Submitted on 1 Mar 2011

HAL is a multi-disciplinary open access archive for the deposit and dissemination of scientific research documents, whether they are published or not. The documents may come from teaching and research institutions in France or abroad, or from public or private research centers.
L'archive ouverte pluridisciplinaire HAL, est destinée au dépôt et à la diffusion de documents scientifiques de niveau recherche, publiés ou non, émanant des établissements d'enseignement et de recherche français ou étrangers, des laboratoires publics ou privés. 


\title{
A Conceptual Framework for the Collaborative Modeling of Networked Manufacturing Systems
}

\author{
Viktor Zaletelj, ${ }^{1,2, *}$ Alojzij Sluga ${ }^{2}$ and Peter Butala ${ }^{2}$ \\ ${ }^{1}$ Trimo, d.d., Prijateljeva 12, 8210 Trebnje, Slovenia \\ ${ }^{2}$ Department of Control and Manufacturing Systems, University of Ljubljana, Faculty of Mechanical Engineering \\ Aškerčeva 6, 1000 Ljubljana, Slovenia
}

\begin{abstract}
A manufacturing system is a product, and has to be designed as any other product. Therefore, a need for adequate methodological support and tools for modeling, structuring, and control of the next generation manufacturing systems is recognized. In this study, the adaptive distributed modeling framework for collaborative design and operations of network manufacturing systems is presented. In manufacturing networks, several autonomous partners participate in dynamic design of a manufacturing system, its implementation, and adaptation. In this context collaborative modeling, structuring, and control in distributed manufacturing environment play a vital role. The proposed modeling framework introduces the common modeling space and enables a collaborative definition of modeling building blocks, model design, simulation, and operations support of distributed manufacturing systems in a dynamic environment - which is the realistic nature of the global manufacturing. The prototype of the framework is elaborated in a case study.
\end{abstract}

Key Words: manufacturing system design, distributed modeling, simulation, modeling framework.

\section{Introduction}

The networking of manufacturing enterprises, especially small and medium enterprises (SMEs), introduces new challenges in manufacturing. These types of networks open new frontiers for competitiveness, innovation, agility, and adaptiveness in the manufacturing business based on: (1) communication, (2) the sharing of information, knowledge, resources, competencies, and risks, (3) mutual understanding and trust, and (4) cooperation and collaboration.

The so-called 'virtual factory' of the future will manufacture in adaptable networks linking original equipment manufacturers with value-chain partners (often SMEs) and suppliers of factory equipment/ services selected according to the needs at a given time. Its composition will not be limited by the presumption of physical co-location, nor by a need to maintain rigid long-term relationships [1].

Such a 'virtual factory' or, better to say, the next generation manufacturing system has to be designed and implemented for each product. Hence, a manufacturing system itself is a product, and has to be designed as

*Author to whom correspondence should be addressed. E-mail: viktor.zaletelj@fs.uni-lj.si

Figures 1-10 appear in color online: http://cer.sagepub.com any other product. There exist several modeling methodologies and tools for the design of mechanical products, (e.g., computer-aided design, manufacturing, and engineering). But do we have modeling methodologies and tools for the design, implementation, and control of such manufacturing systems?

Several outstanding concepts and approaches have been developed in the last 15 years starting with the Yoshikawa's holonic system initiative. An extensive overview is worked out by Ueda et al. [2] and Monostori et al. [3]. The approaches, known as holonic, bionic, fractal, and adaptive, have different origins which impose different approaches. Nevertheless, heterarchical structure and co-operation are essential properties of these paradigms, forming dynamic systems while maintaining overall goal-orientation and coherence.

Therefore, a need for strong methodological support and tools for modeling, structuring, and control of the next generation manufacturing systems is recognized. It is a complex problem of engineering synthesis, which fits within the Ueda's class III problem [4].

The study describes the approach, methodologies, and developed prototype solutions for collaborative and distributed design, modeling, and simulation of manufacturing systems in manufacturing networks. A case study illustrates the approach. 


\section{Background and Motivation}

\subsection{The Role of a Manufacturing System Model}

According to ISO 15704, a model is an abstract representation of reality in any form to present a certain aspect of that reality for answering the questions studied [5].

Modeling is a logical step in the design of a viable manufacturing system with adequate performance. It has to be considered that manufacturing systems are complex systems because of:

- a variety of elements which interact with each other in many ways via information and material flows;

- the dynamic and stochastic nature of the system's environment and the system itself, which introduces uncertainty and does not enable the classical control approach;

- the socio/techno/economic character;

- the short life cycle as it is related to a single product, unlike a life cycle of a traditional factory which exists for several decades; and

- the necessity for continuous adaptation to the needs of customers, events in the environment and in the system, and to changing economic objectives.

One of the main mission of a manufacturing system model is to understand and represent a complex structure and dynamics of the observed system and thus to be able to optimize and control it. A model should provide behavior patterns to be usable for simulation and prediction of future behavior. Here rises the question how deep should modeling go to capture the interested behavior. It is obvious that the quantity of details does not necessary imply better results. On the other side, a too shallow model may not show special behavior patterns. In this contradiction, the ability to estimate the quality aspects of the model is important. As it is not enough to characterize a manufacturing system in terms of its formal dynamics to make an unbiased business decision, the correlations between dynamical patterns and business performance have to be known. Here, a human interaction is needed.

In the field of manufacturing, analytic solutions for a system beyond a very modest level of complexity are unavailable. One way to solve the above-mentioned problem is to use simulation by exploring the effects of changing parameters. The simulation enables designers to experiment with models rather than with real-world systems that would be almost impossible or too costly.

Several simulation techniques exist today which support the manufacturing system simulation and analysis. Usually they cover time, cost, quality, and probability aspects of the corresponding manufacturing system elements (materials, tools, machines, humans, etc.). One very useful methodology with a formal mathematical background is Petri-Net (PN) [6]. Its ability to represent and analyze concurrent as well as distributed models is noteworthy. Lately, PN has extended toward object-oriented principles [7] and different approaches for decentralized simulation evolved from this basis [8]. The agent-based modeling presented in $[9,10]$ exposes some good characteristics, such as self-interest, reactivity, negotiation capability, and autonomy. Artificial intelligence methods, such as neural networks and evolutionary computation open new directions toward system simulation [11].

The discussion until now has been about how to gain an effective manufacturing system model. Nevertheless, is that enough? What is the role of the model when the designed system is implemented?

Design of a manufacturing system within a manufacturing network, composed of autonomous and interacting building blocks, requires a system's approach. Corresponding information communication tools for collaborative design and implementation are needed, in order to keep the consistency of the system. Close interactions between the system and the designers need to be established to enable continuous adaptation to changes and disturbances in the environment or in the system. Therefore, the model should also serve as a control scheme for system operations.

\subsection{Modeling Methodologies}

Modeling methodologies and tools, such as integration definition for function modeling (IDEF) [12], unified modeling language (UML), architecture of integrated information systems, PN, GRAI integrated methodology (Grai-GIM), are widely used today, especially in the field of business process reengineering.

There exist also some interesting initiatives regarding the transformation of a model into a real system, e.g., the model driven architecture and the business modeling integration from OMG group [13]. The corresponding modeling languages, such as the UML, electronic business using extensible markup language (ebXML), BPEL, are based on the web-services (WS) technology. Advanced concurrency concepts for capturing business processes were introduced by Yet Another Workflow Language (YAWL) [14]. Some approaches considering manufacturing networks can be found in the literature. Gou et al. [15] propose a framework for virtual enterprise operation management. Shunk et al. [16] broaden the scope of IDEF modeling from a single to multi-enterprise view.

Different system architectures, such as computer integrated manufacturing (CIM) open system architecture (CIM-OSA), virtual enterprise reference architecture and methodology (VERAM) [17], virtual enterprise architecture reference model (BM_VEARM) [18], 
are being developed to support modeling of manufacturing enterprises. Several EU research projects (ATHENA, ECOLEAD, INTEROP, etc.) address issues of interoperability, service orientation, trust and contract management, networking, reference models, virtual organizations, knowledge management, and business intelligence technologies.

Simulation of distributed systems also attracts some researchers. Wallace et al. [19] introduce non-deterministic control of distributed simulation models. McLean and Riddick [20] propose a database structure to support distributed simulation. Dynamic aspects of models are considered in [21]. Noel and Tichkiewitch [22] introduce the concept of dynamic entities for simultaneous model building.

\subsection{B2MN Environment}

Manufacturing of complex high-tech products, such as industrial and power equipment requires a project-based, engineer-to-order approach to design, development, and production. With respect to high volume products, which are nowadays produced in supply chains in optimized dedicated manufacturing and logistic systems, the project-based products are fabricated in one-of-a-kind or small batch fashion in general-purpose manufacturing systems.

The manufacturing networks, such as extended enterprises [23], promise new possibilities and challenges for manufacturing of these kind of products, where a manufacturing system is not known in advance and has to be structured, optimized, and implemented for each project from scratch.

Owing to their nature, manufacturing networks are characterized as complex adaptive systems [24]. Usually they emerge rather than result from purposeful design by a single entity. In other words, they appear spontaneously on certain patterns of situations and opportunities in an environment where different autonomous entities recognize a need for cooperation within a network. But is this enough for a network to exist and fulfill a mission by effective and efficient network operations? For manufacturing networks it is essential to keep a balance between emergence and control. On the one side, the emergence fosters autonomy of network entities and their self-organization, but too much emergence weakens predictability and manageability of the system. On the other, the control enables predictable and controllable behavior of the system, but too much control limits adaptiveness and innovation.

In order to manage the structural and operational complexity of a manufacturing network and thus the balance between the control and emergence, the business-to-manufacturing-network (B2MN) approach to manufacturing network design and operations is proposed in [25].
In the B2MN approach, the balance is assured with proper design of a network and its building blocks. The design of the network is based on the adaptive distributed manufacturing system concept [26] where an adaptive distributed manufacturing system (ADMS) is structured as a network of autonomous building blocks.

Two levels can be identified in manufacturing networks. The first one is the business level, where projects and project tasks are defined. The second level is the manufacturing systems level. The two levels represent demand and supply which, by nature, are effectively connected by the market mechanism.

Decisions in networks are taken in a distributed way. A partner that would orchestrate operations in the network does not exist. Functionalities, e.g., broking, coordination, and contracting, which did not previously exist to such an extent, have to be implemented [27].

In order to support collaboration in manufacturing networks the corresponding ADMS conceptual framework is proposed in [28]. It introduces autonomous network building blocks, i.e., autonomous work systems (AWS) and a virtual coordination unit (VCU) responsible for mediation and coordination among the building blocks.

In the B2MN the link between the business and manufacturing levels is provided over the marketplace, where the market mechanism governs the distribution of project tasks to candidate AWSs. The coordination of this process is performed by the VCU. AWSs are cooperative and competitive. Cooperativeness provides the basis for planning and coordination and induces controllable behavior while competitiveness provides the basis for negotiation and induces emergent behavior.

In order to support design and operations of ADMSs in the $\mathrm{B} 2 \mathrm{MN}$ environment, the modeling framework is proposed and described in the following.

\section{Adaptive Distributed Modeling Framework - ADMF}

Requirements for developing a modeling framework arise from the characteristics of the next generation manufacturing systems. First of all, it ought to be adaptive and structured by distributed and decentralized autonomous building blocks, being able to operate in dynamic and stochastic environment. So the elementary requirements are: (1) consistent concepts; (2) distributed modeling and simulation functionality to facilitate the integrated and coordinated execution of different simulations, each of which is addressing particular mission in distributed and cooperative decision making; and (3) distributed on line surveillance and monitoring functionality in order to enable transparency and visibility of the system and its structure in real-time. 


\subsection{ADMF Modeling Framework}

The modeling framework is understood as a complete environment for developing and implementing comprehensive adaptive distributed manufacturing systems.

The proposed adaptive distributed modeling framework (ADMF) provides the reference concepts, modeling methods and languages, ontology definition, pre-built reference models, and development tools for customizing and integrating those models to existing ones, as well as for developing and implementing new models. The components of the ADMF are shown in Figure 1, organized in two main parts. On the right side the enabling components are positioned, while on the left different reference models can be found.

\subsubsection{REFERENCE CONCEPTS}

The adopted ADMF concepts are the complex adaptive manufacturing systems (CAMS) concept [29] and the ADMS concept [26], where a manufacturing system is structured as a network of many agents, acting in parallel or/and in series, and constituting a web of interactions.

\subsubsection{MODELING CONCEPTS, METHODOLOGIES, AND LANGUAGES}

The modeling methodologies and languages are designer's tools to navigate between the problem and the solution space. They provide constructs to describe modeling entities, such as works systems, processes, humans, roles, etc., their functional contents as well as supporting information.

Four basic modeling methodologies are used: (1) IDEF0, (2) unified modeling language (UML) class diagram, (3) manufacturing cybernetics, and (4) constraint logic programming (CLP).

\begin{tabular}{|l|l|}
\hline $\begin{array}{l}\text { Reference concepts } \\
\text { CAMS } \\
\text { ADMS }\end{array}$ & $\begin{array}{l}\text { Modeling concepts, } \\
\text { methodologies } \\
\text { and languages } \\
\text { IDEFX, UML, CLP, PN, MAS }\end{array}$ \\
\hline \begin{tabular}{|l|} 
Partial reference work \\
system models
\end{tabular} & $\begin{array}{l}\text { ADMF Ontology } \\
\text { Controlled vocabulary } \\
\text { and reference } \\
D \& M\end{array}$ \\
\hline \begin{tabular}{l|l|} 
Reference work models \\
system models \\
AWSM
\end{tabular} \\
\hline \begin{tabular}{|l} 
Models of ADMS \\
operational systems \\
Cases
\end{tabular} \\
\hline
\end{tabular}

Figure 1. Components of the ADMF.
The IDEF0 methodology [12] is adopted and extended in ADMF into so-called xIDEF0. The extensions are applied to inputs, outputs, controls, and mechanisms, which are substituted with the so-called flow-pipe interfaces of a certain object type. Additional properties, i.e., in/out, push/pull, continuous/discrete, information/material/human, synchronization, and filtering are defined. The flow-pipe objects connect function-blocks and are able to perform custom filtering. Setting of a filter depends dynamically on the model state. The usage of the filters enables creation of branching points (similar to IDEF3). The typified function blocks (transform, transport, store, and compare) enable suggestible building of a model and selective focus and control of the work flow.

A generic xIDEF0 activity diagram is presented in Figure 2. It follows the basic specification of the IDEF0 notation and combines the advantages of the objectoriented programming, state transition diagram, and IDEF3 methodology. xIDEF0 covers the functional description of entities.

The UML class diagram notations are used for defining additional entity properties, methods, relationships (inheritance, association, etc.), and interaction patterns.

As different functionalities are expected in different modeling and/or life cycle phases, a modeling entity has different layers for description of its static and dynamic behavior, as shown on an example of the xIDEF0 function-block in Figure 3.

The functional layer is the basic layer, where properties, expected functionalities, interactions, value-lists, behavior constraints, and relationships to other entities are defined.

The simulation layer is dedicated for evaluation purposes. It defines behavior of the entity while being subjected inside a simulation scenario. There can be more than one simulation layer in the case that different implementations or different views of the entity are possible. These layers provide: (1) designer interaction in case of incomplete information or doubtful decisions of simulation; (2) a systematic way of introducing new entity functionalities that have to be tested; (3) online model update

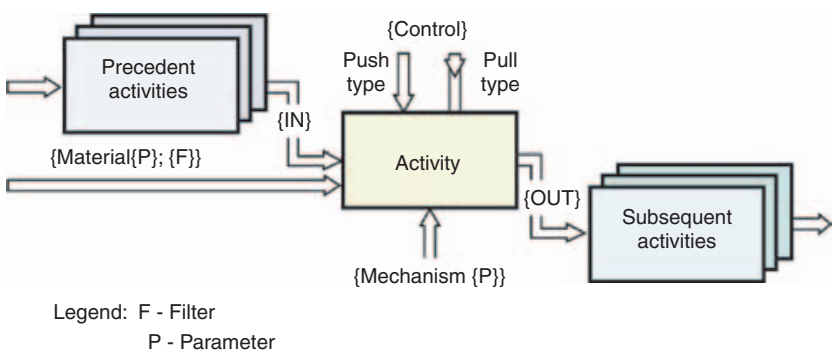

Figure 2. Activity diagram according to the XIDEF0 notation. 
or reconfiguration; (4) prediction capabilities for operative decision making; and (5) information input in the form of a random or statistic function for the simulation scenario in case the entity is a border element of the simulation model.

The execution layer supports operations. It provides the environment for exchange, analysis, and presentation of information for machine-machine (WS interfaces) and machine-human graphic user interaction.

Details of the functional layer are mapped to the simulation and execution layers. These two layers work in parallel and are event driven. They exchange real-life and simulated information. The first are used for updating of manufacturing simulation models. The second enable forming of a comprehensive operational strategy.

Special attention is put on interrelations of entities. In most systems, internal business logic or the underlying database structure itself encapsulate entity relationships, making the system inflexible. This should not be the case for the modeling environment, where introductions, changes, and cancellations of entities occur frequently at all stages of the modeling process.

Therefore, the data about relationships are stored in an adaptive manner. The key point is to define the meaning (semantics) of the relationship dynamically. This is implemented using causality and constraint definitions in CLP. Thus, reasoning about suitable solutions can be achieved by applying the backpropagation mechanism of CLP.

The following example shows one of the basic rules within the modeling environment. Changing the position of physical object $\{\mathrm{Obj}\}$ implies usage of transport activity:
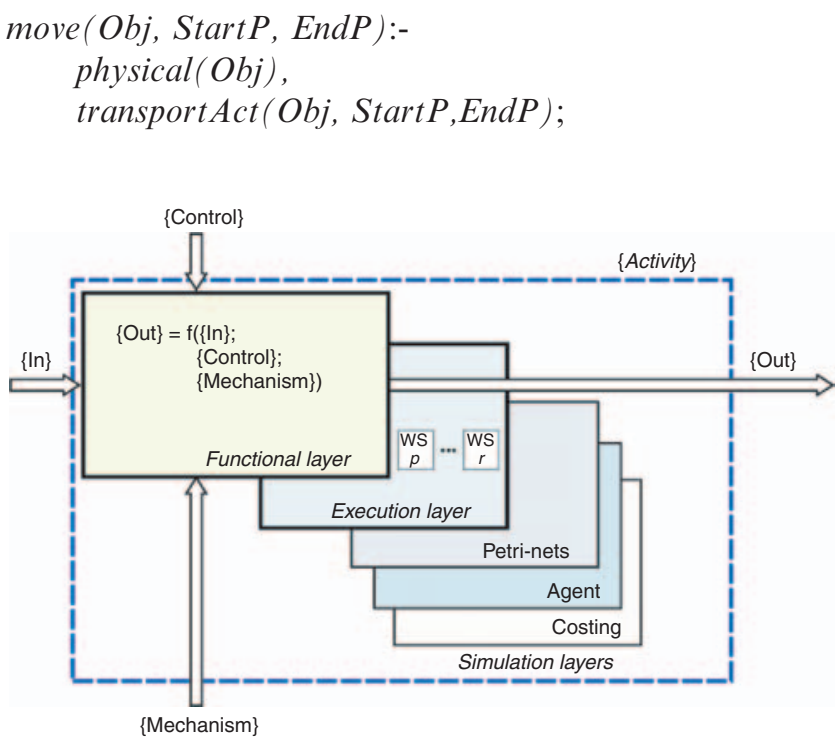

Figure 3. Layers of the modeling entity.
For modeling of manufacturing systems the elementary work system (EWS) concept and notation based on the manufacturing cybernetics is adopted [29]. The EWS concept provides a generic description of elementary manufacturing work systems in terms of interacting structural elements, i.e., manufacturing process, process implementation device, logic controller, sensorics, data and knowledge acquisition, human subject, information and control flow, and their interrelations. Other aspects, such as system's objectives, subject role, control algorithms, and feedbacks are defined as well. Within ADMF, EWS is used as a basic building block for manufacturing level modeling. Thus, it provides a unique feature not found in any other modeling methodology.

Modeling of entities does not start from scratch. Using the reference models, a new entity inherits pre-prepared and considered functionalities like life cycle, version, and history support, etc.

\subsubsection{PARTIAL REFERENCE WORK SYSTEM MODELS (WSPM)}

Following Figure 1, the partial reference work system models capture characteristics common to similar work systems (EWSs). Thereby, these models capitalize previous knowledge and enable reusing of models rather than developing new models from scratch. The partial models make the modeling process more efficient.

\subsubsection{REFERENCE WORK SYSTEM MODELS (AWSM)}

The reference work system models represent registered EWSs within the modeling network. They expose their current states as well as interfaces to the modeling space and thus provide all necessary information for simulation, evaluation, and decisionmaking. When a new project is initiated, Autonomous Work System Models (AWSM) are used as potential structural components of designed distributed manufacturing system.

\subsubsection{MODELS OF ADMS OPERATIONAL SYSTEMS}

The models of ADMS operational systems represent cases of distributed manufacturing systems for certain projects. Either still operative, either finished. In the cases one can find a history of the used components. Therefore, these models provide the knowledge for new ADMS designs.

All presented features are connected with the common data base $(\mathrm{DB})$, which enables dynamic reflections of changes to any of them. The object-oriented class diagram of a portion of the main data structure part is presented in Figure 4. It describes three main areas: (1) the modeling objects definition part, where entity attributes, methods, and relations are defined; 


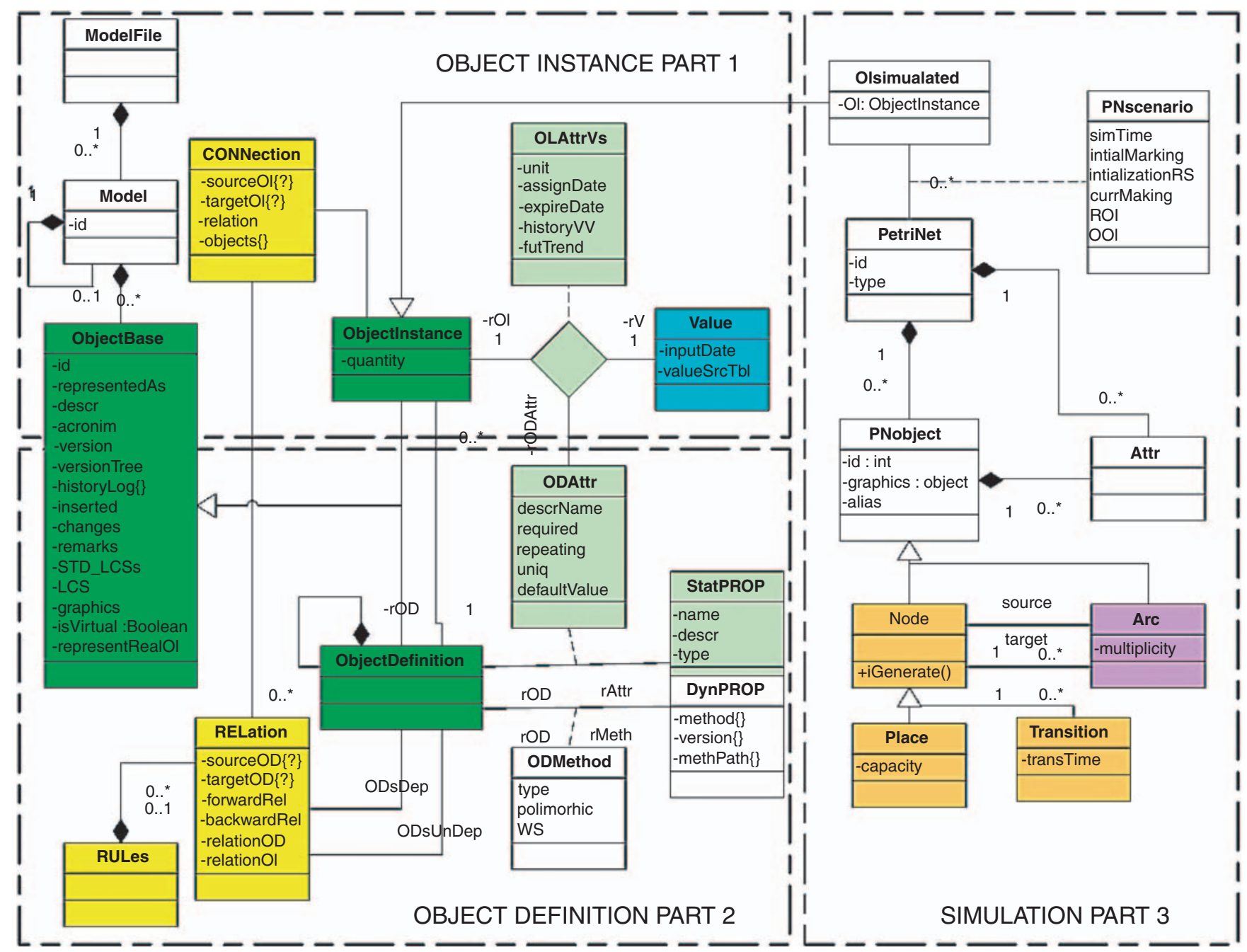

Figure 4. UML class diagram of ADMF data structure.

(2) the objects instance part, where operative instances are described through the values of attributes; and (3) the PN supporting part, where objects for simulation purposes are defined and managed.

High symmetry between the parts (1) and (2) is established. Both inherit from the ObjectBase class that provides common characteristics and thus management functionality.

While the definition part introduces the structure of an entity (objectDefinition), the instantiation part (2) explains how objectInstance-s relies on the part (1). The same is true for the Relation-Connection classes. The relationships are defined between ObjectDefinition classes with the rules in CLP. The connections on the other hand are particular relationships between known ObjectInstances. This way any change is dynamically propagated through the whole system. An interesting feature of such a design is that all information about entities (reference, partial, simulated, active or new) is stored within the same, predefined DB structure. Thus, all entities are manipulated in the same way and what is more, the power of exploring modeling space is increased rapidly.

\subsubsection{ADMS ONTOLOGY}

Another important ADMF component is the ADMF ontology. It provides a controlled vocabulary of the network and behaves as knowledge representation tool. An example of a structure, which defines entities and relations for a project definition, is shown in Figure 5.

\subsection{ADMS Modeling}

The ADMF structure is presented in Figure 6. It consists of two parts: the internal and external one. The internal part is composed of the common modeling space, where collaborative modeling is performed. In the common modeling space, reference work systems models and modeling services can be accessed and activated. The connected data and knowledge base maintains data and rules about models and transactions. 


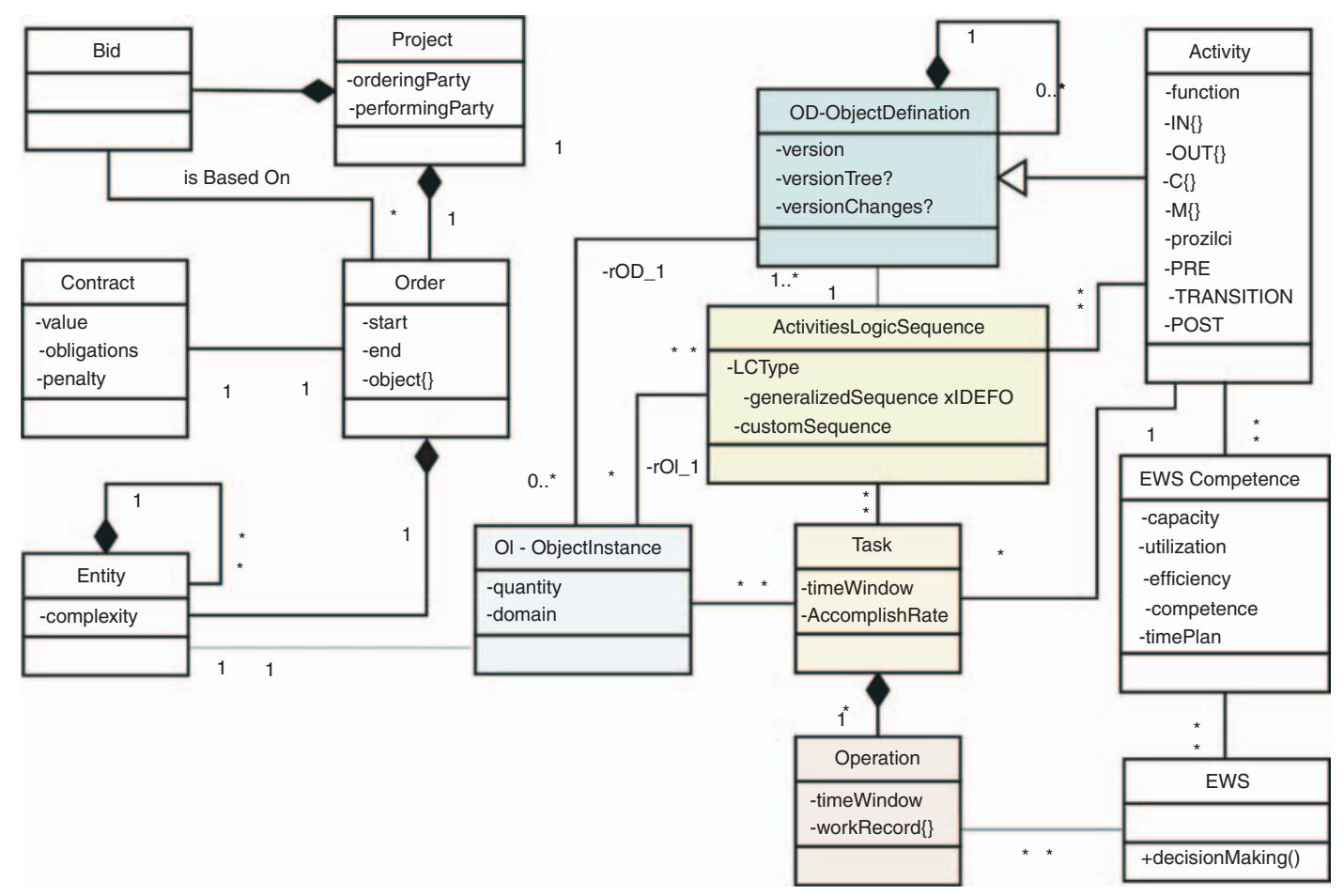

Figure 5. Reference data structure for a project.

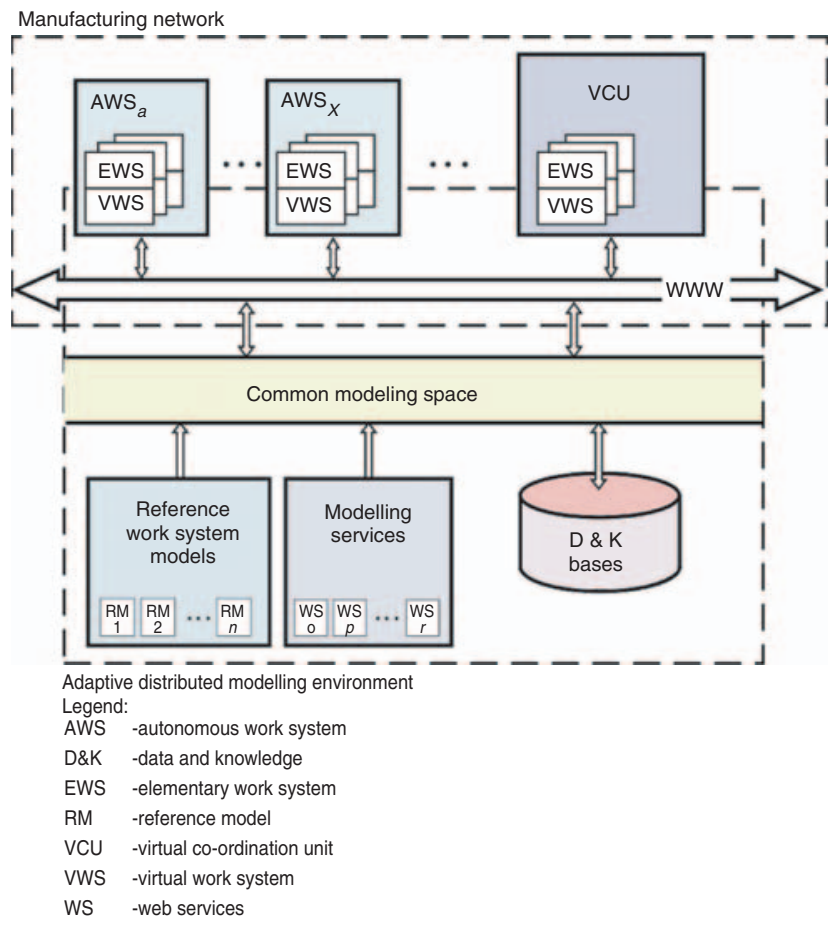

Figure 6. ADMF structure.

The manufacturing network, shown in the upper part of Figure 6, represents the external part of ADMF. It is composed of the AWSs and the VCU. According to the definition [26], AWS is composed of at least one EWS, capable of performing certain manufacturing operations. An EWS is represented in ADMF by its model - virtual work system (VWS) [30], which is a constituent of the ADMF. Thus, the ADMF encompasses all the elements and functionalities needed for modeling of ADMS in a distributed environment.

The common modeling space is connected to the manufacturing network over the web. AWSs autonomously use modeling services, as well as partial reference work system models to build in present their EWSs. Different actors simultaneously participate in the design process, so negotiation and collaboration mechanisms are necessary. Reflections of the user and system actions are propagated through the system, so everyone can be notified about changes, proposals, and other events.

The ADMF implementation for modeling, simulation, and control of ADMS is shown in Figure 7. Design of a new ADMS is activated on a demand from the business level of the B2MN environment. The demand is mediated to AWSs by the VCU. The demand attracts AWSs, which are willing to collaborate in ADMS design. They express their determination by offering EWSs functionalities and capabilities via VWS. These are then candidates for the arising ADMS structure. The results of the ADMS design process are alternative models of ADMS.

Next, the alternative models are simulated and evaluated by the ADMF simulation services. The design solution is selected according to the selected optimization criterion, e.g., minimal costs, shortest 


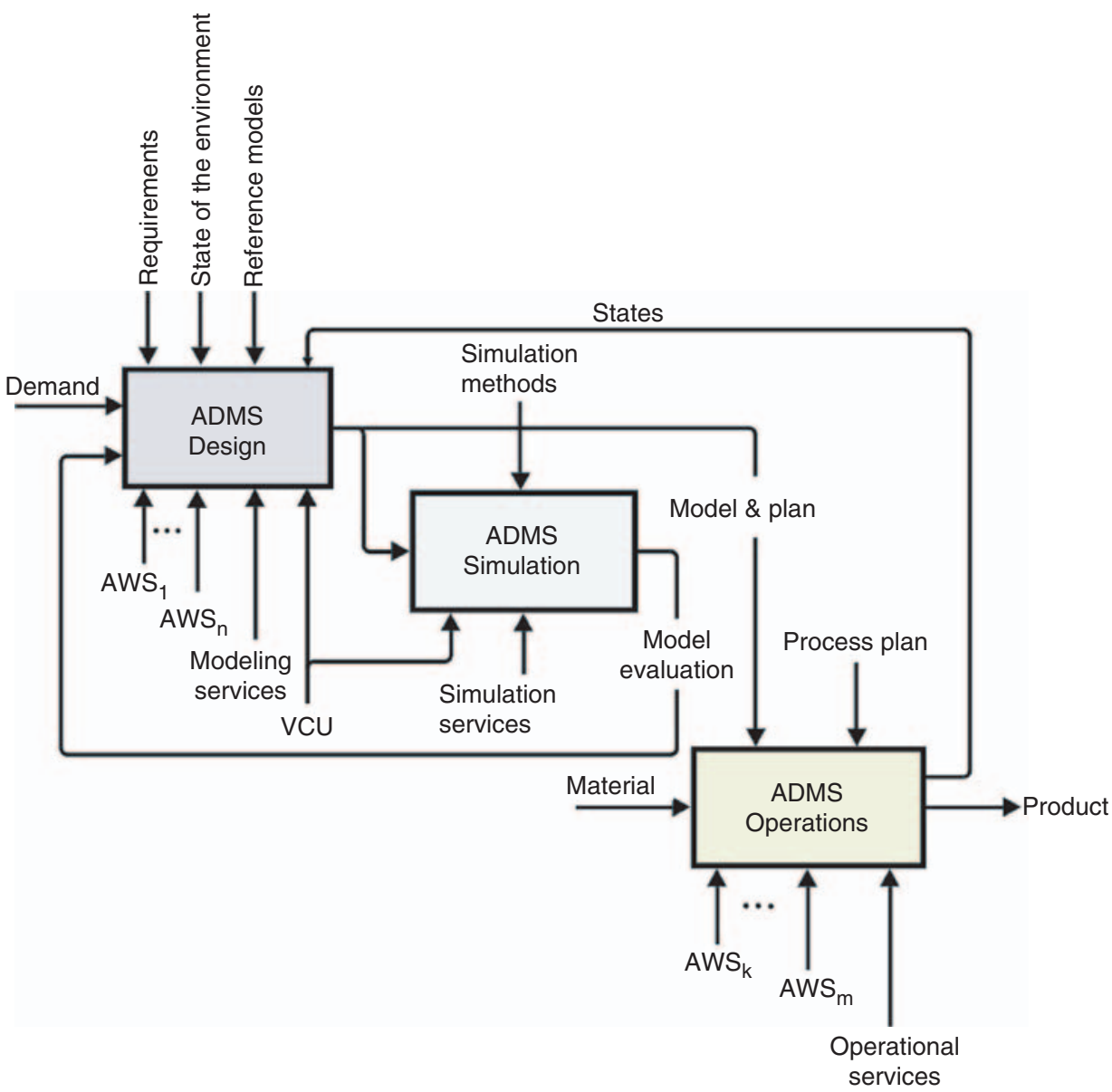

Figure 7. Collaborative ADMS design and operations.

throughput time. The selected model is used as the control roadmap for ADMS operations.

\subsection{Framework Implementation}

A prototype framework application adaptive distributed modeling environment (ADME) is developed as a web environment. It is based on web technologies, such as HTTP and XML.

NET framework is used as a platform for building, deploying, and running the ADME application, which runs on a MS-IIS server. On-the-fly composition of modeling constructs in the web environment using ASP. NET enables real-time human-system interactions. The AJAX technology is applied for collaborative handling of entities and their modification. This way all designers, concurrently working on a model design, know about proposed changes and can thus actively interact and approve or reject proposals or generate new ones. CACHE object-relational data base management system (ORDBMS) acts as the data base management system, and is partially connected with the AMZI!Prolog constraint logic programming environment for entity relationship management.
NET strongly relies on WS technology. The WS technology is applied to integrate various developed services and to provide standardized data interchange interface. For example, the PN service is implemented as one of the core simulation support services of the ADME.

Figure 8 shows the common modeling space in the ADME with an example of a modeling tool for designing work system reference models.

\section{Test Case}

The objective of the case study is to illustrate a part of ADMS modeling process. The ADMS structuring method with the ADMF modeling services is presented.

Consider the following example. Two parts have to be produced in certain time. For each part the due date and corresponding process plan are given. The due date for the part P1 is the 14th time slot and for the P2 is the 21st time slot. The process plan for P1 includes operations 1 and 2 and the process plan for $\mathrm{P} 2$ includes operations 1,2 , and 3 . 


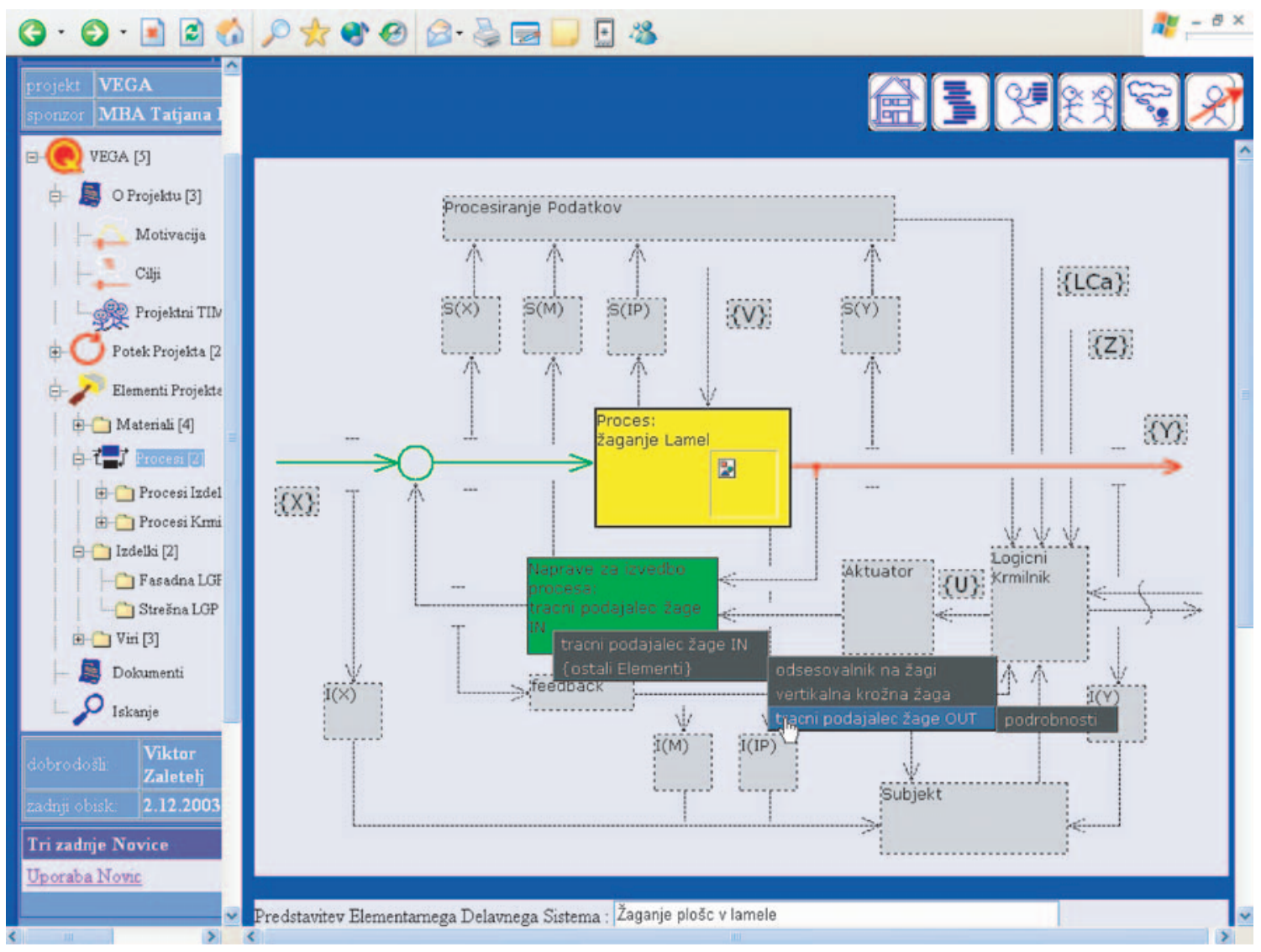

Figure 8. Common modeling space in ADME with the example of a EWS modeling tool.

Table 1. EWS bids data for products $P 1$ and $P 2$.

\begin{tabular}{|c|c|c|c|c|c|c|c|}
\hline \multirow[b]{3}{*}{ EWS } & \multirow[b]{3}{*}{ Operation } & \multicolumn{6}{|c|}{ Part } \\
\hline & & \multicolumn{3}{|c|}{ P1 } & \multicolumn{3}{|c|}{ P2 } \\
\hline & & S\# & Otime & Ocost & S\# & Otime & Ocost \\
\hline 1 & 1 & 1 & 2 & 305 & 1 & 6 & 308 \\
\hline 2 & 1 & 1 & 1 & 483 & 1 & 5 & 340 \\
\hline 2 & 2 & 2 & 3 & 282 & 3 & 2 & 312 \\
\hline 2 & 3 & & & & 2 & 4 & 645 \\
\hline 3 & 3 & & & & 2 & 3 & 702 \\
\hline 4 & 3 & & & & 2 & 3 & 700 \\
\hline
\end{tabular}

Four EWS are candidates for manufacturing of both products. They send bids which include working time [Otime] and costs [Ocost] for each operation/product combination. The bids data are shown in Table 1.

In addition, each EWS gives information about its own schedule in terms of available/unavailable time slots in the give time frame, $\mathrm{TF}=\{0,26\}$, see Figure 9(a).

Based on the parts data and EWSs bids the simulation solver layer performs structuring of the corresponding manufacturing structures for each part. In this case the optimization criterion is the minimal production costs. The optimal results are shown in Figure 9(b) and (c), respectively. Section (b) shows how parts $\mathrm{P} 1$ and $\mathrm{P} 2$ are allocated to EWSs in particular time slots. Section (c) shows the production time frames for both parts. Part 1 is produced in the time frame $\{1,14\}$ with the effective working time of 5 time slots out of 14 , while Part 2 is produced in the time frame $\{0,15\}$ with the effective working time 8 time slots out of 15 , at the minimum costs.

The calculated costs are 1.949 MU for Part 1 and 5.488 MU for Part 2. The simulation solver performs the structuring process in several iteration cycles. The diagram in Figure 10 shows how the results converge toward the optimal solution.

\section{Conclusions}

To gain a competitive advantage on the global market, adaptive distributed manufacturing systems seem to be a promising solution for manufacturing in networks. However, design, structuring, and control of such systems in an effective way are complex tasks.

This study presents the developed ADMF modeling framework for design, structuring, and control of ADMSs in the B2MN environment, which enables the 


\begin{tabular}{|c|c|c|c|c|c|c|c|c|c|c|c|c|c|c|c|c|c|c|c|c|c|c|}
\hline & \multicolumn{22}{|c|}{ Time } \\
\hline EWS & 0 & 1 & 2 & 3 & 4 & 5 & \begin{tabular}{|l|l|}
6 & 7 \\
\end{tabular} & 8 & 9 & 10 & 11 & \begin{tabular}{|l|l|l|}
12 & 13 & 14 \\
\end{tabular} & \begin{tabular}{l|l|}
15 & 16 \\
\end{tabular} & 17 & 18 & 19 & 20 & \begin{tabular}{|l|l|}
21 & 22 \\
\end{tabular} & 23 & 24 & & 26 \\
\hline 1 & & 0 & 0 & & \begin{tabular}{|l|}
0 \\
\end{tabular} & 0 & & & 0 & & 0 & & \begin{tabular}{l|l|}
0 & 0 \\
\end{tabular} & 0 & \begin{tabular}{|l|}
0 \\
\end{tabular} & \begin{tabular}{|l|}
0 \\
\end{tabular} & & & & & 0 & 0 \\
\hline 2 & 0 & & 0 & & & 0 & \begin{tabular}{l|l|}
0 & 0 \\
\end{tabular} & & & 0 & 0 & & & & 0 & 0 & 0 & \begin{tabular}{l|l}
0 & 0 \\
\end{tabular} & 0 & 0 & 0 & 0 \\
\hline 3 & & 0 & & & & 0 & & & 0 & 0 & & & & & & & 0 & & & 0 & 0 & \\
\hline 4 & & & 0 & 0 & & 0 & & & & & 0 & \begin{tabular}{|l|l|}
0 & 0 \\
\end{tabular} & 0 & 0 & 0 & & & & & & & \\
\hline
\end{tabular}

Legend: "blank" = free capacity; 0 = booked time slot

(a) Availability of EWSs in a time frame TF $=\{0,26\}$

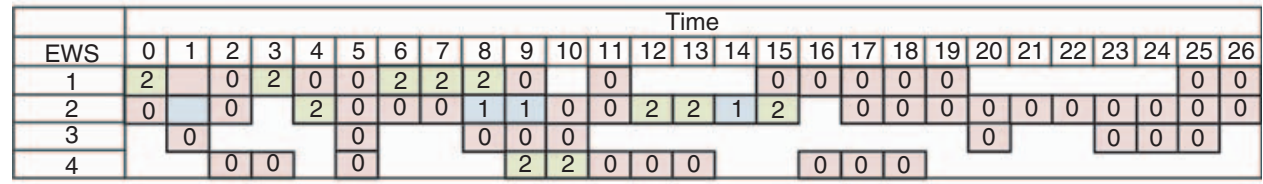

Legend: "blank" = free capacity; 1 or 2 = part assignments

(b) Parts 1 and 2 assignments to EWSs

\begin{tabular}{|c|c|c|}
\hline & \multicolumn{2}{|l|}{ Time } \\
\hline Product & \begin{tabular}{|l|l|l|l|l|l|l|l|l|l|l|l|l|l|l|}
0 & 1 & 2 & 3 & 4 & 5 & 6 & 7 & 8 & 9 & 10 & 11 & 12 & 13 & 14 \\
\end{tabular} & \begin{tabular}{|l|l|l|l|l|l|l|l|l|l|l|l|}
15 & 16 & 17 & 18 & 19 & 20 & 21 & 22 & 23 & 24 & 25 & 26 \\
\end{tabular} \\
\hline$\frac{1}{2}$ & & \\
\hline
\end{tabular}

Legend: production period of parts 1 and 2

(c) Parts 1 and 2 production time frames

Figure 9. (a) Availability, (b) assignment, and (c) production time frames.

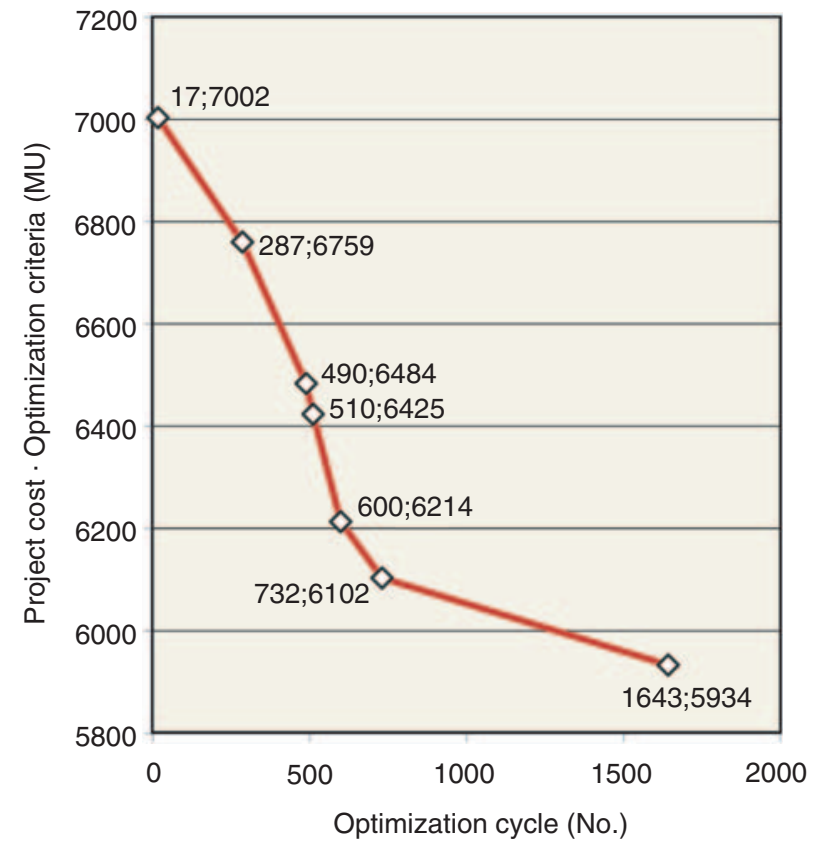

Figure 10. Cost optimization process.

balance between control and emergence in designing adaptive distributed manufacturing systems in networks. The framework represents the complete environment for developing and implementing ADMSs. The ADMF supports all ADMS design phases from definition, modeling, structuring, simulation, and optimization.

The ADMF modeling framework is composed of: (1) reference manufacturing concepts, (2) modeling concepts, methodologies and languages, (3) ontology definition, (4) pre-built reference models, (5) tools for modeling and customizing existing models, and (6) web-based modeling environment ADME.

The ADMF introduces the common modeling space for collaborative ADMS design, control, and adaptation. The design, structuring, and optimization are performed under dynamic environment constraints and in the decentralized, distributed modeling environment, which is the realistic nature of the global manufacturing.

The framework enables effective validation of alternative ADMS structures early in the system development phase. With this capability ADMF supports effective design and operations of the next generation systems.

The ADMF is an open modeling system, where each layer can be customized and additional services can be added. It is important that ADMF explicitly connects the two B2MN levels, i.e., the business and the manufacturing system levels.

In the future, the knowledge-based manufacturing issue will be integrated in the framework. There exists also the possibility to integrate methods and tools, which are being developed within the emergent synthesis concept, on different layers of the framework.

\section{Acknowledgments}

This work was partially supported by the Slovene Ministry of Higher Education, Science, and Technology, Grant No. S2-787-010/21454/2000 and Grant No. 400-17/2004 and inspired by NoE VRL KCiP. 


\section{References}

1. Manufuture High Level Group and Support Group (2006). ManuFuture Platform - Strategic Research Agenda, Assuring the Future of Manufacturing in Europe, Manufuture Conference 2005 "Making it in Europe", Rolls Royce, Derby, UK, December 2005.

2. Ueda, K., Markus, A., Monostori, L., Kals, H.J.J. and Arai, T. (2001). Emergent Synthesis Methodologies for Manufacturing, Annals of the CIRP, 50(2): 335-365.

3. Monostori, L., Vancza, J. and Kumara, S.R.T. (2006). Agent-Based Systems for Manufacturing, CIRP Annals, 55(2): 697-720.

4. Ueda, K. (1999). Synthesis and Emergence, In: Ueda, K. (ed.), Proceedings of the International Workshop on Emergent Synthesis, Kobe, pp. 7-12.

5. ISO 15704 (2000). Industrial Automation Systems Requirements for Enterprise-Reference Architectures and Methodologies. http://www.iso.org/iso/en/Catalogue DetailPage. CatalogueDetail?csnumber $=28777$ (effective link on 3 May 2007).

6. Aalst, W.M.P. and Hee, K.M. (1996). Business Process Redesign: A Petri-net-based Approach, Computers in Industry, 29: 15-26.

7. Liu, D., Wang, J. and Zhang, C.S. (2002). Modelling Workflow Processes with Coloured Petri Nets, Computer in Industry, 49: 267-281.

8. Strassburger, S., Schmidgall, G. and Haasis, S. (2003). Distributed Manufacturing Simulation as an Enabling Technology for the Digital Factory, Journal of Advanced Manufacturing Systems, 2(1): 111-126.

9. Naji, H.R., Etzkorn, L. and Wells, B.E. (2004). Applying Multi-Agent Techniques to Reconfigurable Systems, Advances in Engineering Software, 35: 401-413.

10. Bussmann, S., Jennings, N.R. and Wooldridge, M. (2004). Multiagent Systems for Manufacturing Control. Springer. ISBN-13: 978-3540209249.

11. Fonseca, D.J. and Navaresse, D. (2002). Artificial Neural Networks for Job Shop Simulation, Advanced Engineering Informatics, 16: 241-246.

12. IDEF0 (1993). Function Modelling Method. http://www. idef.com/pdf/idef0.pdf (effective link on 3. May 2007).

13. http://www.omg.org/

14. Aalst, W.M.P. and Hofstede, A.H.M. (2005). YAWL: Yet Another Workflow Language, Information Systems, 30: $245-275$.

15. Gou, H., Biqing, H., Wenhuang, L. and Xiu, L. (2003). A Framework for Virtual Enterprise Operation Management, Computers in Industry, 50: 333-352.

16. Shunk, D.L., Kim, J.-I. and Nam, H.Y. (2003). The Application of an Integrated Enterprise Modeling Methodology - FIDO - to Supply Chain Integration Modeling, Computers \& Industrial Engineering, 45: 167-193.

17. Tølle, M., Zwegers, A. and Vesterager, J. (2003). Virtual Enterprise Reference Architecture and Methodology (VERAM), Global Engineering and Manufacturing in Enterprise Networks (GLOBEMEN) IST-1999-60002, http://cic.vtt.fi/projects/globemen/, http://cic.vtt.fi/projects/ globemen/D41_D43_VERAM_Final.zip

18. Putnik, G.D. (2000). BM Virtual Enterprise Architecture Reference Model, In: Gunasekaran, A. (ed.), Agile Manufacturing: 21st Century Manufacturing Strategy, pp. 73-93, http://www.amazon.com/Agile-Manufac turing-Century-Competitive-Strategy/dp/008043567X.

19. Wallace, D., Yang, E. and Senin, N. (2001). Integrated Simulation and Design Synthesis http://dspace.mit.edu/ handle/1721.1/3802 (effective link on 3 May 2007).

20. McLean, C. and Riddick, F. (2000). The IMS MISSION Architecture for Distributed Manufacturing Simulation, In: Proceedings of the 2000 Winter Simulation Conference, Orlando, Florida, pp. 1539-1548, Orlando, FL, USA, http://ieeexplore.ieee.org/xpl/freeabs_all.jsp?arnumber $=$ 899138.

21. Mentink, R., van Houten, F.J.A.M. and Kals, H.J.J. (2003). Dynamic Process Management for Engineering Environments, CIRP Annals, 52(1): 351-354.

22. Noel, F. and Tichkiewitch, S. (2004). Shared Dynamic Entities Technology to Support Distant Coordination in Design Activity, CIRP Annals, 53(1): 163-166.

23. Jagdev, H.S. and Browne, J. (1998). The Extended Enterprise - A Context for Manufacturing, Production Planning \& Control, 9(3): 216-229.

24. Choi, T.Y., Dooley, K.J. and Rungtusanatham, M. (2001). Supply Networks and Complex Adaptive Systems, Journal of Operations Management, 19: 351-366.

25. Butala, P. and Sluga, A. (2002). Dynamic Structuring of Distributed Manufacturing Systems, Advanced Engineering Informatics, 16(2): 127-133.

26. Butala, P. and Sluga, A. (2006). Autonomous Work Systems in Manufacturing Networks, CIRP Annals, 55(1): 521-524.

27. Wiendahl, H.P. and Lutz, S. (2002). Production in Networks, Annals of the CIRP, 51(2): 573-586.

28. Sluga, A., Butala, P. and Peklenik, J. (2005). A Conceptual Framework for Collaborative Design and Operations of Manufacturing Systems. Annals of the CIRP, 54(1): 437-440.

29. Peklenik, J. (1995). Complexity in Manufacturing Systems, Manufacturing Systems, 24(1): 17-25.

30. Sluga, A., Butala, P. and Bervar, G. (1998). A Multi-agent Approach to Process Planning and Fabrication in Distributed Manufacturing, Computers \& Industrial Engineering, 35: 455-458.

\section{Viktor Zaletelj}

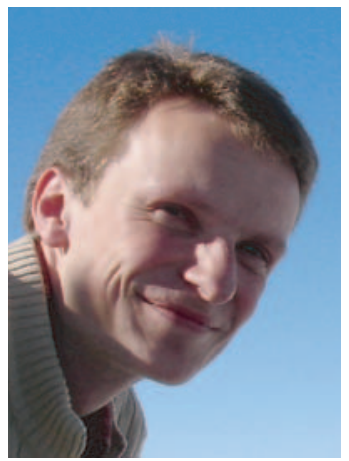

Viktor Zaletelj received his BS and MS from University of Ljubljana in Manufacturing Engineering. His research interests include advanced manufacturing theory and systems, adaptive manufacturing systems modeling, collaborative information system, and corresponding computing system design. He is currently an active partner in two European projects, E!3450 qSPAI (Quality Control In The Production Line of Sandwich Panels With Ai Methods) and NoE VRL-KCiP. He is the head of 
system development at the company Trimo, and a researcher at the Faculty of Mechanical Engineering.

\section{Alojzij Sluga}

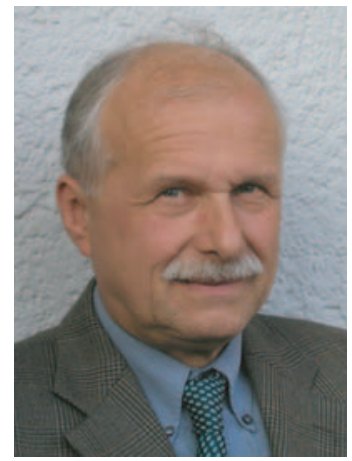

Alojzij Sluga is professor of Manufacturing Engineering at the Faculty of Mechanical Engineering, University of Ljubljana, Slovenia. $\mathrm{He}$ heads the Laboratory for Manufacturing Cybernetics and Experimentation. He has worked with different industries in areas of manufacturing technology, computer integrated manufacturing, and production management and control. His current research interest includes enterprise modeling, virtual manufacturing, networked organizations, and quality systems and technology. He has published over 100 research papers. He has been scientific responsible for the University of Ljubljana of the EUREKA project TRUST 'Use Of Regional Potentials With Respect to Problem-Solving Processes in Production' and of the Network of Excellence VRLKCiP 'Virtual Research Lab for a Knowledge Community in Production' funded by the European Community. $\mathrm{He}$ is a member of SATENA (Slovenian Academic Society for Technology and Natural Science) and associate member of the
International Academy for Production Engineering CIRP.

\section{Peter Butala}

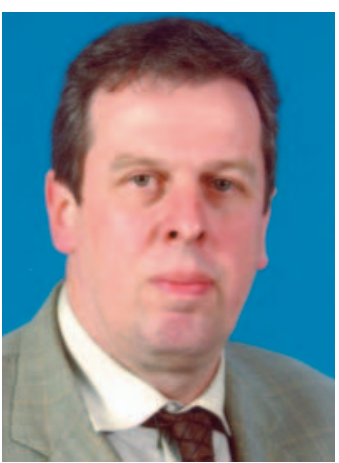

Peter Butala is currently a docent at the Faculty of Mechanical Engineering, University of Ljubljana, Slovenia. He earned his MS and $\mathrm{PhD}$ in mechanical engineering at University of Ljubljana.

He spent several years in industry as an R\&D manager. Now, he is heading the Laboratory of Control and Manufacturing Systems. His current research interests are mechatronic systems, manufacturing and assembly systems, digital factory, virtual manufacturing and manufacturing networks. He managed several national projects and three international EUREKA projects. Currently he heads on the national level the EU FP 6 project 'European Virtual Center for Innovation Excellence Assessment - VIVA' and the EUREKA E! 3781 project 'Development, engineering, design and test of a prototype of a storage-commissioning-system for drugs and applications - APOMAT' $\mathrm{He}$ is also a member of the research team of the Network of Excellence VRL KCiP 'Virtual Research Lab for a Knowledge Community in Production' funded by the European Community. 